\title{
Z-99 High-resolution geophysical surveying at the Springfield Fault, New Zealand
}

P. CORBOZ ${ }^{1}$, H. HORSTMEYER ${ }^{1}$, J. TRONICKE ${ }^{1}$,D. NOBES ${ }^{2}$, J. CAMPBELL ${ }^{2}$, A.G. GREEN ${ }^{1}$

${ }^{1}$ ETH Zurich, Institute of Geophysics, ETH Hoenggerberg, 8093 Zurich, Switzerland

${ }^{2}$ Department of Geological Sciences, University of Canterbury, PB 4800, Christchurch, New Zealand

\begin{abstract}
To trace the active Springfield Fault (South Island, New Zealand) and map its character at shallow depths on a terrace where it exhibits no surface expression, we recorded 3-D georadar data across an approximately rectangular 110 x 40 m survey area. In addition, we carried out multi-electrode geoelectric measurements along a $198 \mathrm{~m}$ long profile that crossed the georadar survey area. Although the georadar depth penetration was limited to only $\sim 5 \mathrm{~m}$, the processed images revealed the presence of a prominent reflecting horizon disrupted by three main discontinuities. Semi-continuous subhorizontal reflection patterns were interpreted to represent sedimentary units within the fluvial deposits, whereas three detected discontinuities were interpreted as fault traces with small near-vertical offsets $(\sim 0.4 \mathrm{~m})$. This interpretation was supported by vertical and lateral changes visible on the final inverted resistivity model indicating lithological boundaries and fault branches.
\end{abstract}

\section{Introduction}

Much of the Canterbury region (South Island, New Zealand) is located within a zone of active earth deformation associated with the oblique collision between the Australian and Pacific tectonic plates. Holocene movement on major faults and other evidence of late Quaternary movement show that the area is tectonically active. The focus of the present study is a southwesterly extension of the Springfield Fault located in the Canterbury plains west of Christchurch. The Springfield Fault is part of a system consisting of interconnected eastnortheast trending strike-slip transfer faults, oblique thrust and/or reverse faults with associated fault-propagated folds. In our surveying area, the Springfield Fault exhibits no surface expression and is buried beneath sediments comprising fluvial terraces. To image the shallow subsurface and to identify the buried Springfield Fault, 3-D georadar and multielectrode geoelectric measurements are used.

\section{Data acquisition and processing}

3-D georadar data were collected using a semi-automated georadar system (Lehmann and Green, 1999) and $100 \mathrm{MHz}$ antennas. To avoid data clipping an antenna spacing of $2.0 \mathrm{~m}$ was used. We have investigated an approximately rectangular 110 x $40 \mathrm{~m}$ area which was subdivided into eight individual parts measured successively within eight days (Figure 1). Trace spacing was $\sim 0.2 \mathrm{~m}$ in inline and $\sim 0.25 \mathrm{~m}$ in crossline direction, respectively. In total, nine CMP measurements (recorded at the end of the surveying period) were used to obtain subsurface velocity information. No major variations were detected and we used a mean velocity of $0.075 \mathrm{~m} / \mathrm{ns}$ for further processing (i.e., migration and time-to-depth conversion). 
Processing of our 3-D georadar data followed a rather standard processing flow. However, after adjusting the air wave and stacking/gridding the data on a regular $0.2 \times 0.25 \mathrm{~m}$ grid significant time shifts appeared in subsurface events between some of the eight surveying parts. These time-shifts can be explained by changing weather conditions (from rain and snow in the beginning to sunny and dry at the end of the survey) resulting in significant variations of water content and thus of georadar velocities in the uppermost soil layers. As our CMP measurements were all carried out on the last surveying day, they could not be used for correcting these velocity variations. Alternatively, we performed a cross-correlation analysis of adjacent traces in the 20-60 ns time window to identify present time-shifts. Two major shifts were recognized and corrected with respective static time adjustments. Further standard processing included amplitude scaling, bandpass filtering, F-XY deconvolution, normal moveout corrections and 3-D phase-shift migration.

To retrieve information on the electric properties of the sediments and to assist the interpretation of the georadar data, a 2-D electrical resistivity survey has been carried out along a profile crossing the 3-D georadar survey area (Figure 1). The data have been collected with a multi-electrode system using 100 electrodes with a spacing of $2.0 \mathrm{~m}$. We have combined Dipole-Dipole- (using dipole spacings of 2, 4 and $8 \mathrm{~m}$ ), Schlumberger- and Wenner-configurations to optimize the information content of the final inverted resistivity model. For a combined inversion of all recorded configurations (4145 data points), we employ the commercially available Res2Dinv inversion software (Loke and Barker, 1996).

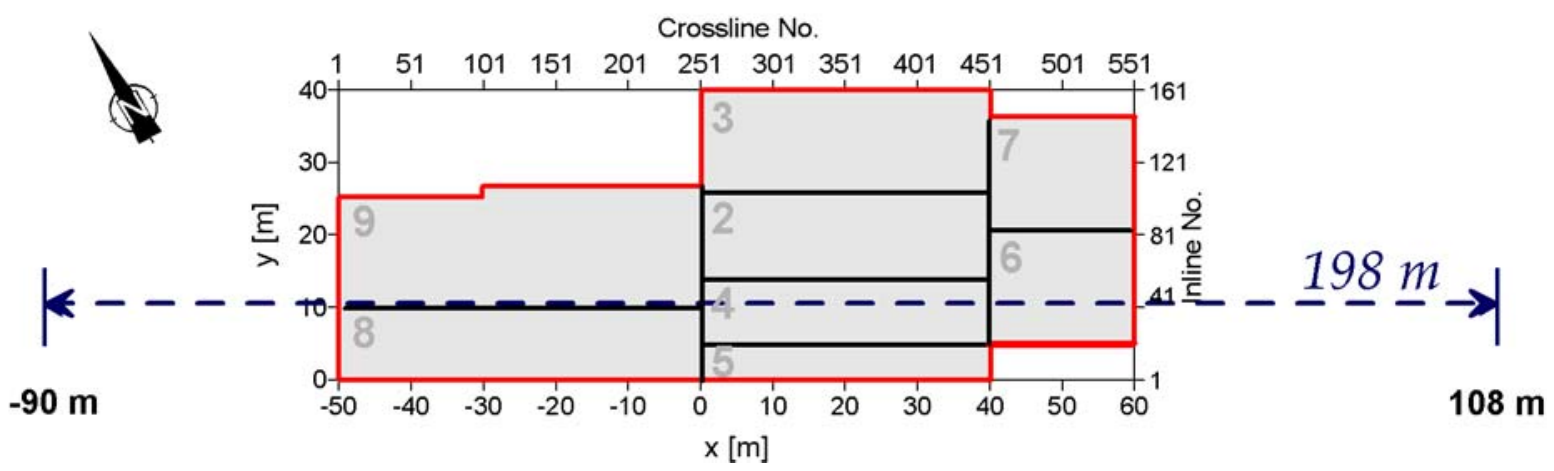

Figure 1: Layout of performed geophysical surveys. Shaded area represents the 3-D georadar survey comprising of eight individual parts (grey numbers 2-9). The resistivity profile (dashed line) crosses the 3-D georadar field at inline 41.

\section{Results and Interpretation}

Figure 2 shows a typical inline section from the migrated georadar data set. Maximum depth penetration is $\sim 150 \mathrm{~ns}(\sim 5.5 \mathrm{~m})$ and the image reveals the overall layered character of the fluvial deposits. A1, A2 and A3 indicate main discontinuities and offsets of the picked shallow reflection H1. The two depth slices shown in Figure 3 illustrate that A1-A3 separate areas with distinctive different reflection patterns. For example, west of A1 continuous parallel to subparallel reflections are present, whereas the area east of A1 is characterized by a more disturbed and discontinuous reflection pattern (see also Figure 2).

Figure 4 presents the part of our final inverted resistivity model corresponding to the subsurface area imaged by georadar profile shown Figure 2. Considering the results of our georadar survey, we interpret a $\sim 1 \mathrm{~m}$ thick top soil layer underlain by a $\sim 3$ m thick layer of fluvial sediments characterized by increased resistivity values. The decrease in resistivities at $\sim 5$ m depth corresponds well to the maximum depth of penetration of the georadar data and is interpreted as the boundary between unconsolidated sediments and bedrock. Main lateral 
variation in electrical resistivity can be described by zones Z1 $(\sim 200-2000 \mathrm{Ohm} \cdot \mathrm{m})$ and Z2 ( 1000-6000 Ohm $\cdot \mathrm{m})$. Comparing Figure 4 with Figures 2 and 3 illustrates that $\mathrm{Z} 1$ is characterized by continuous reflections, whereas $\mathrm{Z} 2$ is characterized by a more disturbed and discontinuous reflection pattern.

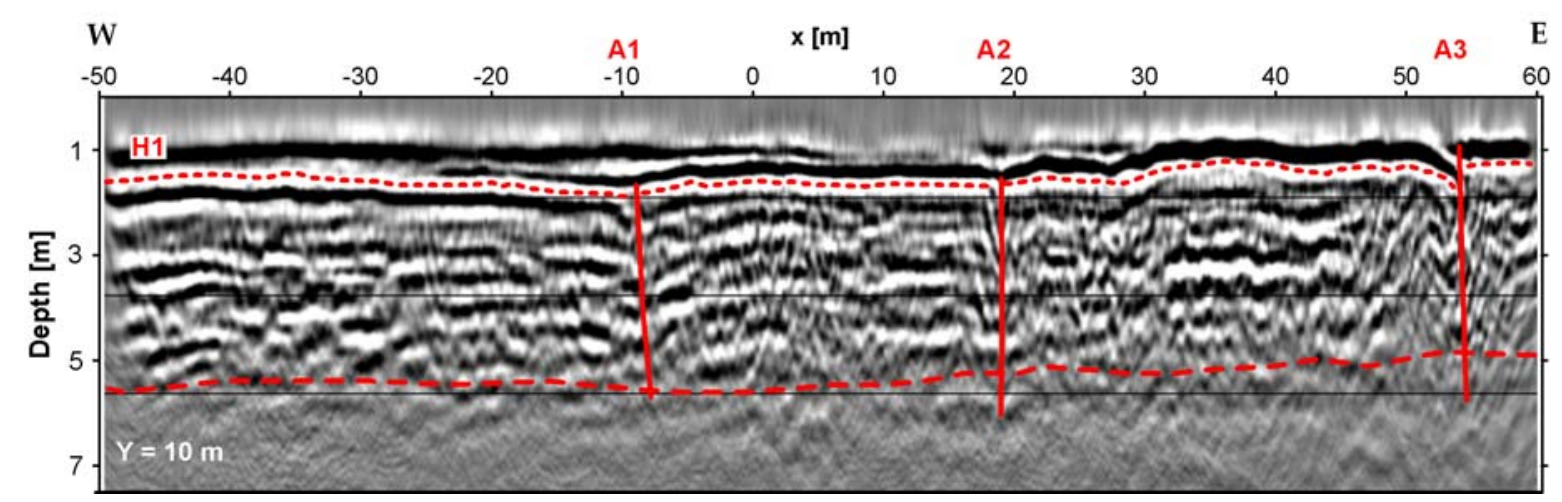

Figure 2: Typical inline profile extracted from the processed 3-D georadar data. A1-A3 label interpreted major discontinuities and $\mathrm{H} 1$ the picked shallow reflection event.

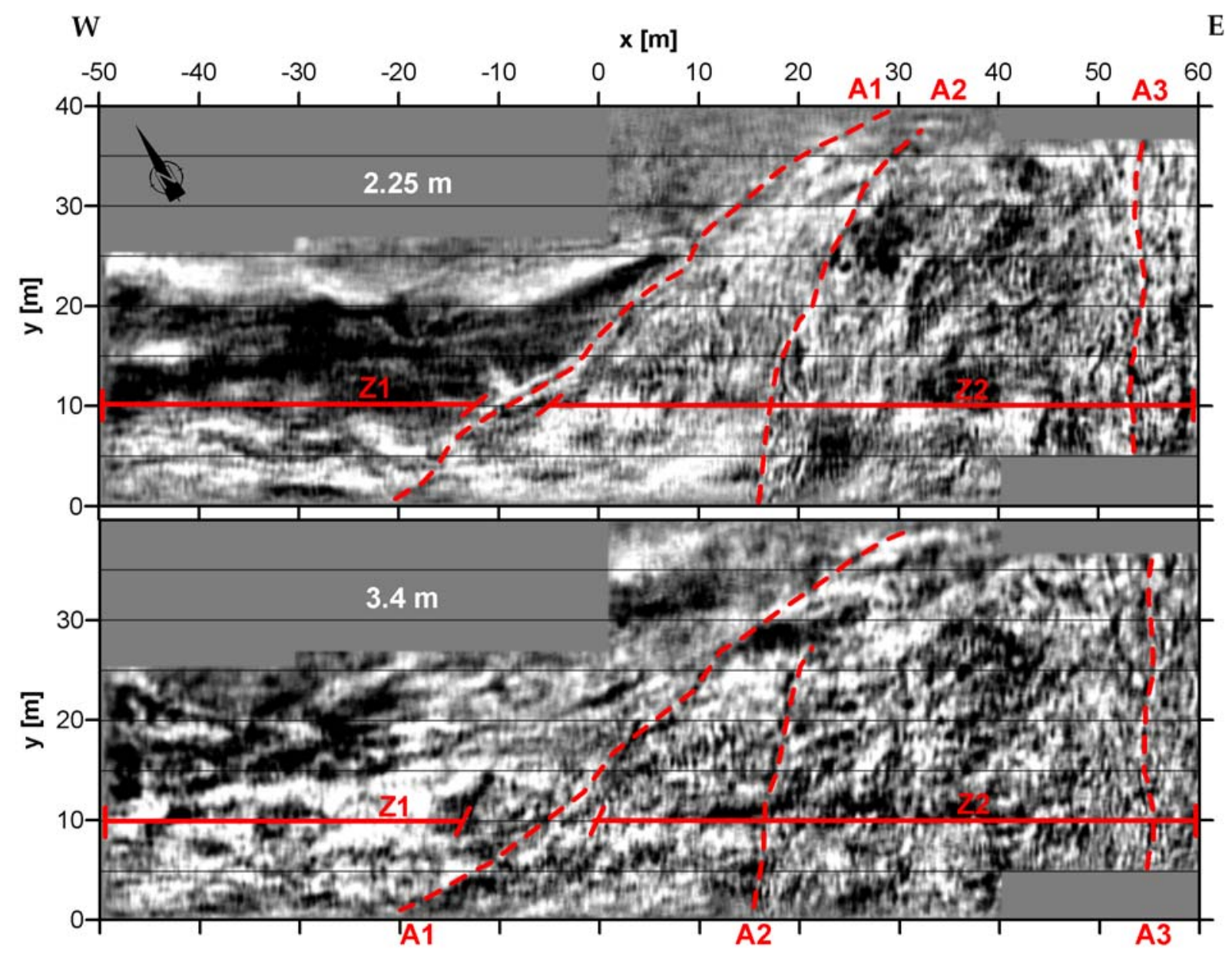

Figure 3: Typical depth slices at 2.25 and $3.4 \mathrm{~m}$ depth extracted from the processed georadar data. A1-A3 label interpreted major discontinuities while lateral zones Z1 and Z1 are interpreted from the final resistivity model. 


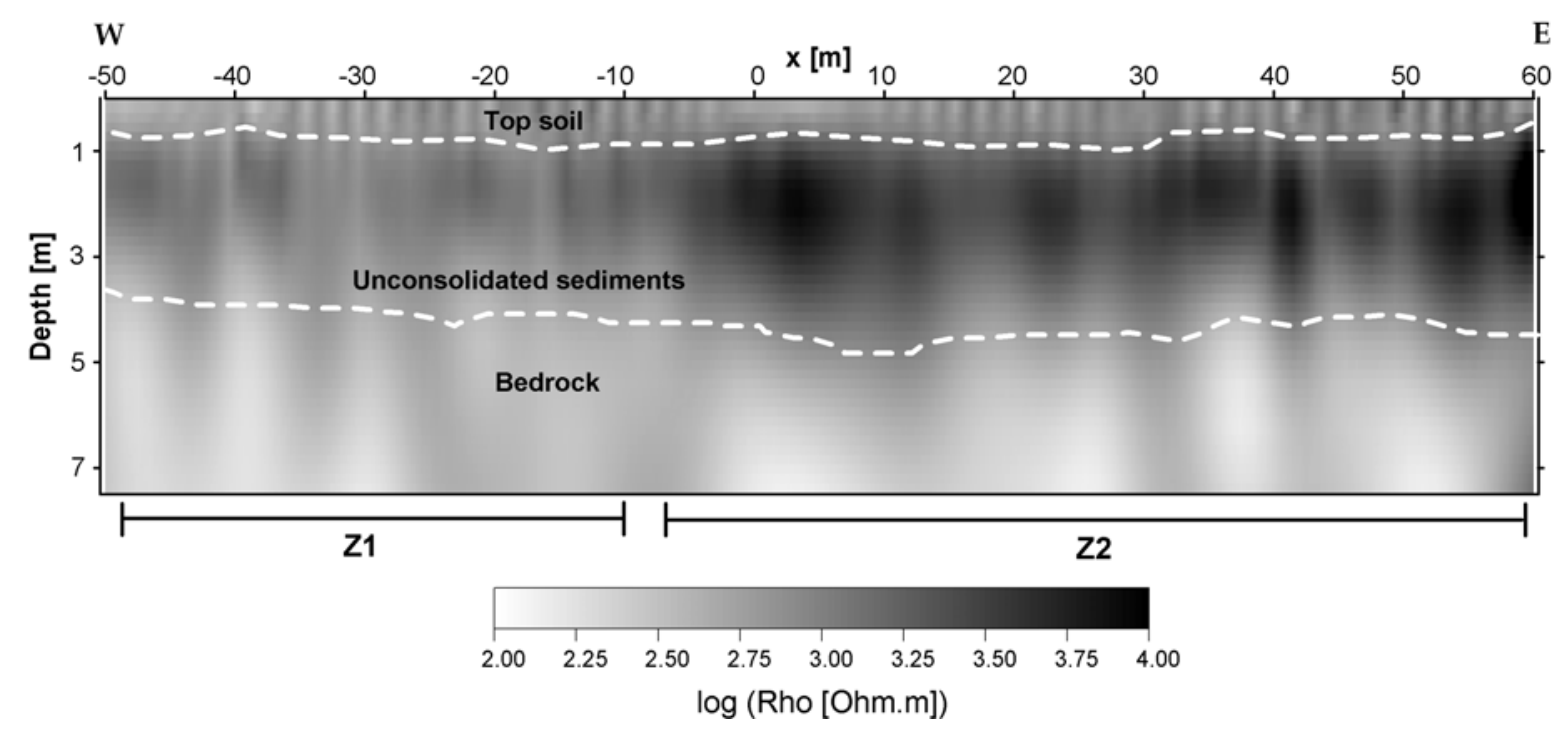

Figure 4: Part of the final inverted resistivity model corresponding to the georadar profile shown in Figure 2. White dashed lines indicate layer boundaries interpreted from the georadar and the electric data. Interpreted zones Z1 and Z2 indicate the main lateral variation of the electrical resistivity within the fluvial sediments. Note the logarithmic grayscale corresponds to a range of 100 to $10,000 \mathrm{Ohm} \cdot \mathrm{m}$.

\section{Conclusion}

We have collected 3-D georadar data and a 2-D electric survey to image the shallow subsurface at a site where the active Springfield Fault exhibits no surface expression and is buried beneath fluvial sediments. In the processed 3-D georadar data and in the inverted electric resistivity model, strong discontinuities and lateral variations have been detected. Main georadar discontinuities A1-A3 are interpreted as traces of the buried Springfield Fault with minor vertical offsets. This interpretation is supported by our electric resistivity model. Ground-truth information as provided for example by trenching and/or drilling (on the basis of our geophysical results) could further improve our subsurface model of the site and should be used to confirm our interpretation.

\section{Acknowledgements}

We thank M. Finnemore from the University of Canterbury, Christchurch for supporting our work in New Zealand. This research was supported by the Swiss National Science Foundation.

\section{References}

Lehmann, F. and Green, A.G., 1999, Semi-automated georadar data acquisition in three dimensions, Geophysics, 64, 719-731.

Loke, M.H. and Barker, R.D., 1996. Rapid least-squares inversion of apparent resistivity pseudosections by a quasi-Newton method. Geophysical Prospecting, 44, 131-152. 